\title{
Luminescence of Europium Complexes with Triazole-Containing Ligands
}

\author{
Jae Hoon Kim, ${ }^{a}$ A. I. Dalinger, ${ }^{a}$ A. V. Medvedko, ${ }^{a}$ E. V. Latipov, ${ }^{a, b}$ S. Z. Vatsadze, ${ }^{a}$ and V. V. Utochnikova ${ }^{*, a}$ \\ a Lomonosov Moscow State University, Moscow, Russian Federation \\ ${ }^{b}$ Institute of Nanotechnology of Microelectronics, Russian Academy of Sciences, Moscow, Russian Federation
}

Email: valentina.utochnikova@gmail.com (V. V. U.)

Abstract In the present work, eleven new complexes of europium and terbium with substituted azoles ligands were obtained as candidates for sensor materials for phosphinoxide. As a result, a new material with high sensitivity of up to $9 \% / \mu \mathrm{L}$ was obtained.

Keywords luminescence, europium, sensor, triazole, triphenylphosphine oxide

\section{Introduction}

The unique luminescent properties of lanthanide coordination compounds (CCs) make them ideal materials for sensor applications. ${ }^{[1-3]}$ Indeed, unlike any other class of compounds, in particular organic dyes, they demonstrate high Stokes shift values and narrow emission bands, which allow easy to separate the excitation beam and emitted light easily. The constant position of the bands, the unique lanthanide property, allows exact tuning of the detectors. Europium complexes are often used due to the combination of high photoluminescence quantum yields (PLQYs). ${ }^{[4-6]}$ Among these materials, aromatic carboxylates $^{[7-12]}$ and $\beta$-diketonates ${ }^{[13-16]}$ play an important role due to high PLQYs values and high chemical stability. Very little attention is paid to complexes with $\mathrm{NH}$-acid anions as anionic ligands. At the same time, the use of europium CCs in bioimaging often involves obtaining conjugates based on them, for example, containing biologically active fragments such as peptoids. ${ }^{[17-19]}$ Conjugation is often carried out by the reaction of azide-alkyne Huisgen cycloaddition, ${ }^{[20-23]}$ during which a triazole-containing compound is formed. However, the role of triazole in lanthanide luminescence is also poorly understood.

Thus, the purpose of this work was to study the luminescent properties of a number of europium compounds with pyrazole and triazole-containing ligands (Figure 1). The corresponding core is marked in red. The substituent variation was selected to adjust the luminescent properties, in particular luminescence intensity. Ligand $\mathrm{H}_{2} \mathrm{~L}^{7}$ was added to the set of ligands to investigate the luminescence dependence on the presence of pyrazole, not only triazole. $\mathrm{HL}^{2}$ was additionally used to compare the role of triazole with tetrazole. Two CCs of terbium, as well as a CC with a tetrazole-containing ligand, are also included in the study.

Owing to listed unequaled properties, lanthanide CCs are very promising materials with a number of applications including sensor materials. Among the sensor materials, sensors for phosphine oxides are important since a number of chemical warfare agents such as sarin and soman correspond to this class of compounds. ${ }^{[24]}$ The search of sensors for the materials is preferable to avoid working with them directly. As a substitute for the selected phosphine oxides, another phosphine oxide, namely triphenylphosphine oxide (TPPO), was used in the present work. ${ }^{[25]}$ The objective of the work was to obtain complexes with very good sensory properties. In particular, they should have sufficient luminescence intensity to ensure the

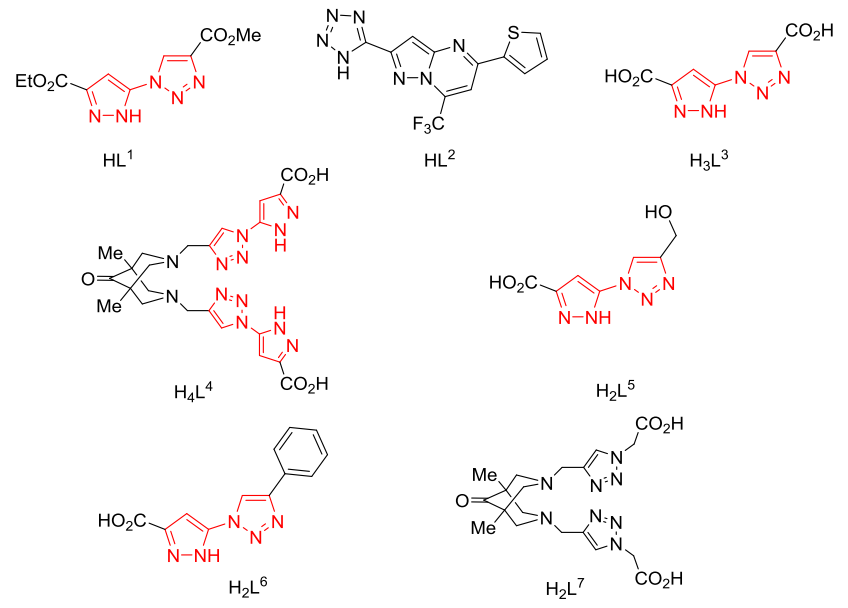

Figure 1 Selected ligands.

possibility of its quenching by TPPO. On the other hand, the luminescence should not be very intense, so that the quenching effect would be significant.

\section{Experimental}

\section{Materials and methods}

Sodium ascorbate and methyl propiolate were purchased from abcr; $t-\mathrm{BuOH}, \mathrm{THF}, \mathrm{DCM}$, EtOAc, $\mathrm{CuSO}_{4} \cdot 5 \mathrm{H}_{2} \mathrm{O}, \mathrm{HCl}$ and $\mathrm{KOH}$ were obtained from IREA 2000 ; $\mathrm{EuCl}_{3} \cdot 6 \mathrm{H}_{2} \mathrm{O}, \mathrm{TbCl}_{3} \cdot 6 \mathrm{H}_{2} \mathrm{O}$, and 1,10-phenanthroline (Phen) were achieved from Sigma Aldrich. Precursors were used without additional purification.

IR spectra were registered on a Thermo Scientific Nicolet iS5 FTIR spectrometer with iD1 Transmission and iD7 ATR (diamond) accessories. ${ }^{1} \mathrm{H}$ NMR and ${ }^{13} \mathrm{C}$ NMR spectra were acquired on Bruker Avance $400(400$ and $101 \mathrm{MHz}$, respectively), Bruker DRX-500 (500 and $126 \mathrm{MHz}$, respectively), Bruker AM-300 (300 and $75 \mathrm{MHz}$, respectively), and Bruker Avance IIIHD 500 (500 and $126 \mathrm{MHz}$, respectively) spectrometers at $298 \mathrm{~K}$ (unless other temperature is indicated). For ${ }^{1} \mathrm{H}$ NMR and ${ }^{13} \mathrm{C}$ NMR, TMS was used as internal standard. Mass spectra were recorded on a Finnigan MAT INCOS-50 (direct injection, El, $70 \mathrm{eV}$ ) mass spectrometer. High-resolution mass spectra were recorded on a Bruker MicroOTOFII mass spectrometer with electrospray ionization. Elemental analysis 
was performed on a PerkinElmer Series II $2400 \mathrm{CHNS/O}$ analyzer. Melting points were determined by the capillary method on Stuart SMP20 and Electrothermal IA9000 apparatuses. Monitoring of reaction progress and assessment of the purity of synthesized compounds were done by TLC on Merck TLC Silica gel 60G F254 plates. Carl Roth Silica gel 60, $0.04-0.063 \mathrm{~mm}$, was used for column chromatography. Thermal analysis with mass-detection of the evolved gases was performed on a Netzsch STA449 F1 + QMS403 Aelos thermal analyzer. Luminescence and excitation spectra were measured with the Fluorolog 3 spectrofluorometer over excitation with a xenon lamp.

\section{Synthesis}

Methyl 1-[3-(ethoxycarbonyl)-1H-pyrazol-5-yl]-1H-1,2,3triazole-4-carboxylate $\left(\mathrm{HL}^{1}\right)$. Ethyl 5-azido-1 $\mathrm{H}$-pyrazole-3carboxylate (obtained as in Ref. [26]) $(1.7 \mathrm{mmol})$ and methyl propiolate $(1.7 \mathrm{mmol})$ were dissolved in $t$-BuOH $(4 \mathrm{~mL})$. A solution of sodium ascorbate ( $34 \mathrm{mg}, 0.17 \mathrm{mmol}, 10 \mathrm{~mol} \%$ ) in $\mathrm{H}_{2} \mathrm{O}(2 \mathrm{~mL})$ was added with vigorous stirring to the reagent solution. The flask was evacuated and filled with argon. A solution of $\mathrm{CuSO}_{4} \cdot 5 \mathrm{H}_{2} \mathrm{O}(21 \mathrm{mg}, 0.085 \mathrm{mmol}, 5 \mathrm{~mol} \%)$ in $\mathrm{H}_{2} \mathrm{O}(2 \mathrm{~mL})$ was then added to the reaction mixture. The reaction mixture was stirred at $25^{\circ} \mathrm{C}$ for $12 \mathrm{~h}$, and the mixture was poured into ice water. The formed precipitate was filtered off and washed with a small amount of $\mathrm{H}_{2} \mathrm{O}$, then dried in a vacuum desiccator over $\mathrm{P}_{2} \mathrm{O}_{5}$. The filtrate was extracted with EtOAc. Then, the organic phase was separated and dried over anhydrous $\mathrm{Na}_{2} \mathrm{SO}_{4}$. The dried organic phase was evaporated under reduced pressure on the rotary evaporator to afford a solid. Both solids were combined. Yield $390 \mathrm{mg}(86 \%)$, beige solid, m.p. 190-191 ${ }^{\circ} \mathrm{C}$. IR (KBr) $v_{\max }: 3196(\mathrm{NH}), 1719(\mathrm{C}=\mathrm{O}), 1684$ $(\mathrm{C}=\mathrm{O}) \mathrm{cm}^{-1} .{ }^{1} \mathrm{H}$ NMR $\left(400 \mathrm{MHz}\right.$, DMSO- $\left.d_{6}\right) \delta: 14.59(1 \mathrm{H}, \mathrm{s}, \mathrm{NH})$, $9.28(1 \mathrm{H}, \mathrm{s}, \mathrm{H}-5$ triazole), $7.29(1 \mathrm{H}, \mathrm{s}, \mathrm{H}-4$ pyrazole $), 4.35(2 \mathrm{H}$, q, $\left.J=6.9 \mathrm{~Hz}, \mathrm{OCH}_{2} \mathrm{CH}_{3}\right), 3.86\left(3 \mathrm{H}, \mathrm{s}, \mathrm{OCH}_{3}\right), 1.33(3 \mathrm{H}, \mathrm{t}, J=$ $\left.6.9 \mathrm{~Hz}, \mathrm{OCH}_{2} \mathrm{CH}_{3}\right) .{ }^{13} \mathrm{C}$ NMR (101 MHz, DMSO- $\left.d_{6}\right) \delta: 160.4$, 158.2, 145.4, 139.2, 135.4, 127.4, 100.6, 61.5, 52.1, 14.1. HRMS (ESI): calcd for $\mathrm{C}_{10} \mathrm{H}_{12} \mathrm{~N}_{5} \mathrm{O}_{4}[\mathrm{M}+\mathrm{H}]^{+}$266.0884, found 266.0886. Calcd for $\mathrm{C}_{10} \mathrm{H}_{11} \mathrm{~N}_{5} \mathrm{O}_{4}$ : C 45.29, H 4.18, N 26.41. Found: C 45.31, H 4.08, N 26.43.

\section{5-[4-(Hydroxymethyl)-1H-1,2,3-triazol-1-yl]-1H-pyrazole-}

3-carboxylic acid $\left(\mathrm{H}_{2} \mathrm{~L}^{5}\right)$. Ethyl 5-[4-(hydroxymethyl)-1 $\mathrm{H}-1,2,3-$ triazol-1-yl]-1H-pyrazole-3-carboxylate (obtained as in Ref. [26]) $(0.0019 \mathrm{~mol})$ was dissolved in aqueous $\mathrm{KOH}(330 \mathrm{mg}, 0.0059$ $\mathrm{mol} ; 25 \mathrm{~mL}$ of solution). The formed solution was stirred at $60{ }^{\circ} \mathrm{C}$ for $12 \mathrm{~h}$. Then, the solution was passed through a thin layer of silica gel and acidified by $2 \mathrm{M}$ aqueous $\mathrm{HCl}$ to $\mathrm{pH} 1$. The formed precipitate was filtered off and dried in a vacuum desiccator over $\mathrm{P}_{2} \mathrm{O}_{5}$. The filtrate was extracted with EtOAc, then the organic phase was separated and dried over anhydrous $\mathrm{Na}_{2} \mathrm{SO}_{4}$. The dried organic phase was evaporated under reduced pressure on the rotary evaporator to afford a solid. Both solids were combined. Yield $318 \mathrm{mg}(80 \%)$, orange solid, m.p. $264-265{ }^{\circ} \mathrm{C}$. IR (KBr) $v_{\max }: 3213(\mathrm{OH}), 2971-2350$ $(\mathrm{COOH}), 1699(\mathrm{C}=\mathrm{O}) \mathrm{cm}^{-1}$. ${ }^{1} \mathrm{H}$ NMR $\left(400 \mathrm{MHz}, \mathrm{DMSO}-d_{6}\right) \delta$ : $14.27(1 \mathrm{H}, \mathrm{s}, \mathrm{NH}), 13.81(1 \mathrm{H}$, br. s, $\mathrm{COOH}), 8.45(1 \mathrm{H}, \mathrm{s}, \mathrm{H}-5$ triazole), $7.11\left(1 \mathrm{H}, \mathrm{s}, \mathrm{H}-4\right.$ pyrazole), $5.29\left(1 \mathrm{H}\right.$, br. s, $\left.\mathrm{CH}_{2} \mathrm{OH}\right)$, $4.58\left(2 \mathrm{H}, \mathrm{s}, \mathrm{CH}_{2} \mathrm{OH}\right) .{ }^{13} \mathrm{C}$ NMR (101 MHz, DMSO-d $\left.d_{6}\right) \delta: 160.0$, 148.7, 146.2, 136.6, 120.9, 99.4, 54.8. HRMS (ESI): calcd for $\mathrm{C}_{7} \mathrm{H}_{8} \mathrm{~N}_{5} \mathrm{O}_{3}[\mathrm{M}+\mathrm{H}]^{+} 210.0622$, found 210.0614 .

5-(4-Phenyl-1H-1,2,3-triazol-1-yl)-1H-pyraz-ole-3-carboxylic acid $\left(\mathrm{H}_{2} \mathrm{~L}^{6}\right)$. Ethyl 5-(4-phenyl-1H-1,2,3-triazol-1-yl)-1Hpyrazole-3-carboxylate(obtained as in Ref. [26]) $(0.0019 \mathrm{~mol})$ was dissolved in aqueous $\mathrm{KOH}(330 \mathrm{mg}, 0.0059 \mathrm{~mol} ; 25 \mathrm{~mL}$ of solution). The formed solution was stirred at $60{ }^{\circ} \mathrm{C}$ for $12 \mathrm{~h}$. Then, the solution was passed through a thin layer of silica gel and acidified by $2 \mathrm{M}$ aqueous $\mathrm{HCl}$ to $\mathrm{pH} 1$. The formed precip- itate was filtered off and dried in a vacuum desiccator over $\mathrm{P}_{2} \mathrm{O}_{5}$. The filtrate was extracted with EtOAc, and the organic phase was separated and dried over anhydrous $\mathrm{Na}_{2} \mathrm{SO}_{4}$. The dried organic phase was evaporated under reduced pressure on the rotary evaporator to afford a solid. Both solids were combined. Yield $344 \mathrm{mg}(71 \%)$, colourless solid, m.p. $269-270{ }^{\circ} \mathrm{C}$. IR (KBr) $v_{\max }: 3141(\mathrm{NH}), 2985(\mathrm{OH}), 1689(\mathrm{C}=\mathrm{O}) \mathrm{cm}^{-1} .{ }^{1} \mathrm{H}$ NMR $\left(400 \mathrm{MHz}, \mathrm{DMSO}-d_{6}\right) \delta: 14.38(1 \mathrm{H}, \mathrm{s}, \mathrm{NH}), 13.88(1 \mathrm{H}, \mathrm{br} . \mathrm{s}$, $\mathrm{COOH}), 9.18(1 \mathrm{H}, \mathrm{s}, \mathrm{H}-5$ triazole), $7.98(2 \mathrm{H}, \mathrm{d}, J=7.3 \mathrm{~Hz}, \mathrm{H}$ $\mathrm{Ph}), 7.48(2 \mathrm{H}, \mathrm{t}, J=7.5 \mathrm{~Hz}, \mathrm{H} \mathrm{Ph}), 7.37(1 \mathrm{H}, \mathrm{t}, J=7.3, \mathrm{H} \mathrm{Ph})$ $7.19\left(1 \mathrm{H}, \mathrm{s}, \mathrm{H}-4\right.$ pyrazole). ${ }^{13} \mathrm{C}$ NMR $\left(101 \mathrm{MHz}\right.$, DMSO- $\left.d_{6}\right) \delta$ : 159.8, 146.9, 146.2, 136.5, 130.0, 129.0, 128.4, 125.5, 119.5, 99.6. HRMS (ESI): calcd for $\mathrm{C}_{12} \mathrm{H}_{10} \mathrm{~N}_{5} \mathrm{O}_{2}[\mathrm{M}+\mathrm{H}]^{+}$256.0829, found 256.0834

1-(3-Carboxy-1 H-pyrazol-5-yl)-1 H-1,2,3-tri-azole-4-carboxylic acid $\left(\mathrm{H}_{3} \mathrm{~L}^{3}\right)$. Methyl 1-[3-(ethoxycarbonyl)-1H-pyrazol-5yl]-1H-1,2,3-triazole-4-carboxylate (obtained as in Ref. [26]) $(0.0019 \mathrm{~mol})$ was dissolved in aqueous $\mathrm{KOH}(330 \mathrm{mg}, 0.0059$ $\mathrm{mol} ; 25 \mathrm{~mL}$ of solution). The formed solution was stirred at $60{ }^{\circ} \mathrm{C}$ for $12 \mathrm{~h}$. Then, the solution was passed through a thin layer of silica gel and acidified by $2 \mathrm{M}$ aqueous $\mathrm{HCl}$ to $\mathrm{pH} 1$. The formed precipitate was filtered off and dried in a vacuum desiccator over $\mathrm{P}_{2} \mathrm{O}_{5}$. The filtrate was extracted with EtOAc. Then, the organic phase was separated and dried over anhydrous $\mathrm{Na}_{2} \mathrm{SO}_{4}$. The dried organic phase was evaporated under reduced pressure on the rotary evaporator to afford a solid. Both solids were combined. Yield $340 \mathrm{mg}(80 \%)$, colourless solid, m.p. $190-191^{\circ} \mathrm{C}$. IR (KBr) $v_{\max }: 3142(\mathrm{NH}), 3088-2526$ $(\mathrm{COOH}), 1694(\mathrm{C}=\mathrm{O}) \mathrm{cm}^{-1}$. ${ }^{1} \mathrm{H}$ NMR $\left(400 \mathrm{MHz}, \mathrm{DMSO}-d_{6}\right) \delta$ : $14.38(1 \mathrm{H}, \mathrm{s}, \mathrm{NH}), 13.59(2 \mathrm{H}$, br. s, $\mathrm{COOH}), 9.13(1 \mathrm{H}, \mathrm{s}, \mathrm{H}-5$ triazole), $7.20\left(1 \mathrm{H}, \mathrm{s}, \mathrm{H}-4\right.$ pyrazole). ${ }^{13} \mathrm{C}$ NMR $(101 \mathrm{MHz}$, DMSO- $\left.d_{6}\right) \delta: 161.4,159.7,145.5,140.3,136.6,127.1,100.4$. HRMS (ESI): calcd for $\mathrm{C}_{7} \mathrm{H}_{6} \mathrm{~N}_{5} \mathrm{O}_{4}[\mathrm{M}+\mathrm{H}]^{+}$224.0414, found 224.0414.

5,5'-\{4,4'-[(1,5-Dimethyl-9-oxo-3,7-diazabicyclo[3.3.1]nonane-3,7-diyl)bis(methylene)]bis(1H-1,2,3-t-riazole-4,1diyl)\}bis(1H-pyrazole-3-carboxylic acid) hydrochloride dihydrate $\left(18 \cdot \mathbf{H C l} \cdot 2 \mathrm{H}_{2} \mathrm{O}\right)\left(\mathrm{H}_{4} \mathrm{~L}^{4}\right)$. Diethyl 5,5'-\{4,4'-[(1,5-dimethyl9-oxo-3,7-diazabicyclo[3.3.1]nonane-3,7-diyl)bis(methylene)]bi$\mathrm{s}(1 \mathrm{H}$-1,2,3-triazole-4,1-diyl)\}bis $(1 \mathrm{H}$-pyrazole-3-carboxylate) (obtained as in Ref. [26]) (1.543 g, $0.0025 \mathrm{~mol}$ ) was dissolved in aqueous $\mathrm{KOH}(0.56 \mathrm{~g}, 0.01 \mathrm{~mol} ; 25 \mathrm{~mL}$ of solution). The formed solution was stirred at $70{ }^{\circ} \mathrm{C}$ for $24 \mathrm{~h}$. Then, the solution was passed through a thin layer of silica gel and acidified by $2 \mathrm{M}$ aqueous $\mathrm{HCl}$ to $\mathrm{pH} 2-3$. The formed beige precipitate was filtered off, washed with a small amount of cold $\mathrm{H}_{2} \mathrm{O}$, and dried in a vacuum desiccator over $\mathrm{P}_{2} \mathrm{O}_{5}$ to constant weight. Yield 933 mg (68\%), light-grey solid, m.p. $267-268^{\circ} \mathrm{C}$. IR (KBr) v: 3111 $(\mathrm{OH}), 1713(\mathrm{C}=\mathrm{O}) \mathrm{cm}^{-1}$. ${ }^{1} \mathrm{H}$ NMR $\left(400 \mathrm{MHz}, \mathrm{DMSO}-d_{6}\right) \delta: 14.28$ $(2 \mathrm{H}, \mathrm{s}, \mathrm{NH}), 11.52(2 \mathrm{H}$, br. s, $\mathrm{COOH}), 8.80(2 \mathrm{H}, \mathrm{s}, \mathrm{H}-5$ triazole $)$, $7.11\left(2 \mathrm{H}, \mathrm{s}, \mathrm{H}-4\right.$ pyrazole), $4.24\left(4 \mathrm{H}, \mathrm{s}, 2 \mathrm{NCH}_{2}\right), 3.62(4 \mathrm{H}, \mathrm{d}, J=$ $10.6 \mathrm{~Hz}, 2 \mathrm{CH}_{2}$ bispidine), $2.96\left(4 \mathrm{H}, \mathrm{d}, J=10.6 \mathrm{~Hz}, 2 \mathrm{CH}_{2}\right.$ bispidine), $0.87\left(6 \mathrm{H}, \mathrm{s}, 2 \mathrm{CH}_{3}\right) .{ }^{13} \mathrm{C}$ NMR $\left(126 \mathrm{MHz}, \mathrm{DMSO}-d_{6}\right) \delta$ : 208.7, 159.8, 146.0, 139.4, 137.1, 123.7, 99.2, 62.2, 49.6, 45.6, 16.0. HRMS (ESI): calcd for $\mathrm{C}_{23} \mathrm{H}_{27} \mathrm{~N}_{12} \mathrm{O}_{5}[\mathrm{M}+\mathrm{H}]^{+} 551.2222$, found 551.2213. Calcd for $\mathrm{C}_{23} \mathrm{H}_{31} \mathrm{ClN}_{12} \mathrm{O}_{7}$ : C 44.34, H 5.02, N 26.98. Found: C 44.40; H 5.50; N 26.90.

Diethyl 2,2'-(4,4'-((1,5-dimethyl-9-oxo-3,7-diazabicyclo[3.3.1]nonane-3,7-diyl)bis(methylene))bis(1H-1,2,3-triazole4,1-diyl))diacetate $\left(\mathbf{H}_{\mathbf{2}} \mathbf{L}^{7}\right)$. 1,5-Dimethyl-3,7-di(prop-2-yn-1-yl)3,7-diazabicyclo[3.3.1]nonan-9-one (obtained as in Ref. [26]) $(732 \mathrm{mg}, 3.0 \mathrm{mmol}$ ) and ethyl 2-azidoacetate $(774 \mathrm{mg}, 6.0$ mmol) were dissolved in $7.5 \mathrm{~mL}$ of tert-butanol under argon. Solutions of sodium ascorbate $(160 \mathrm{mg}, 0.3 \mathrm{mmol}$ ) in $1.9 \mathrm{~mL}$ of water and $\mathrm{CuSO}_{4} \cdot 5 \mathrm{H}_{2} \mathrm{O}$ in $1.9 \mathrm{~mL}$ of water were added sequentially. A reaction mixture was stirred at $r$.t. for $24 \mathrm{~h}$. The 
solution was evaporated to dryness and quenched with $50 \mathrm{~mL}$ of $\mathrm{DCM}$ and $10 \mathrm{~mL}$ water. The organic layer was separated and washed with several portions of $15 \mathrm{~mL}$ of water until discoloration of water layer. The organic layer was dried over sodium sulfate and evaporated to dryness. Yield $1.103 \mathrm{~g}(73 \%)$, sticky oil. ${ }^{1} \mathrm{H}$ NMR (400 MHz, DMSO- $\left.d_{6}\right) \delta: 7.96(2 \mathrm{H}, \mathrm{s}, \mathrm{H}-5$ triazole), $5.35\left(4 \mathrm{H}, \mathrm{s}, \underline{\mathrm{CH}_{2}} \mathrm{CO}_{2}\right), 4.16\left(4 \mathrm{H}, \mathrm{t}, J=7.2 \mathrm{~Hz}, \mathrm{CH}_{2} \mathrm{CH}_{3}\right), 3.64$ $\left(4 \mathrm{H}, \mathrm{s}, \mathrm{NCH}_{2}\right), 2.98\left(4 \mathrm{H}, \mathrm{d}, J=10.6 \mathrm{~Hz}, 2 \mathrm{CH}_{2}\right.$ bispidine $), 2.32$ $\left(4 \mathrm{H}, \mathrm{d}, J=10.6 \mathrm{~Hz}, 2 \mathrm{CH}_{2}\right.$ bispidine $), 1.19(6 \mathrm{H}, \mathrm{d}, J=7.2 \mathrm{~Hz}$, $\left.\mathrm{CH}_{2} \underline{\mathrm{CH}}_{3}\right), 0.83\left(6 \mathrm{H}, \mathrm{s}, 2 \mathrm{CH}_{3}\right) .{ }^{13} \mathrm{C}$ NMR $\left(101 \mathrm{MHz}, \mathrm{DMSO}-d_{6}\right) \delta$ : 214.3, 167.2, 143.4, 125.1, 64.4, 61.4, 51.0, 50.3, 45.9, 20.0, 14.0. HRMS (ESI): calcd for $\mathrm{C}_{23} \mathrm{H}_{35} \mathrm{~N}_{8} \mathrm{O}_{5}[\mathrm{M}+\mathrm{H}]^{+}$503.2730, found 503.2735 .

Potassium 2,2'-(4,4'-((1,5-dimethyl-9-oxo-3,7-diazabicyclo[3.3.1]nonane-3,7-diyl)bis(methylene))bis(1H-1,2,3-triazole-4,1-diyl))diacetate $\left(\mathrm{K}_{2} \mathrm{~L}^{7}\right) \cdot \mathrm{H}_{2} \mathrm{~L}^{7}(706 \mathrm{mg}, 1.4 \mathrm{mmol}$ ) was dissolved in $11 \mathrm{~mL}$ of THF and $3.23 \mathrm{~mL}$ of aqueous $0.87 \mathrm{M}$ $\mathrm{KOH}$ solution was added. The reaction mixture was refluxed overnight and evaporated to dryness. Yield $730 \mathrm{mg} \mathrm{(99 \% ),}$ white powder. ${ }^{1} \mathrm{H}$ NMR $\left(400 \mathrm{MHz}\right.$, DMSO- $\left.d_{6}\right) \delta: 7.73(2 \mathrm{H}, \mathrm{s}, \mathrm{H}-5$ triazole), $4.57\left(4 \mathrm{H}, \mathrm{s}, \underline{\mathrm{CH}}_{2} \mathrm{CO}_{2}\right), 3.58\left(4 \mathrm{H}, \mathrm{s}, \mathrm{NCH}_{2}\right), 2.98(4 \mathrm{H}, \mathrm{d}$, $J=10.7 \mathrm{~Hz}, 2 \mathrm{CH}_{2}$ bispidine), $2.31\left(4 \mathrm{H}, \mathrm{d}, J=10.6 \mathrm{~Hz}, 2 \mathrm{CH}_{2}\right.$ bispidine), $0.83\left(6 \mathrm{H}, \mathrm{s}, 2 \mathrm{CH}_{3}\right) .{ }^{13} \mathrm{C}$ NMR $\left(101 \mathrm{MHz}\right.$, water- $\left.d_{2}\right) \delta$ : $220.5,172.4,142.0,125.8,63.7,52.8,49.6,46.3,18.1$. Calcd for $\mathrm{C}_{19} \mathrm{H}_{24} \mathrm{~K}_{2} \mathrm{~N}_{8} \mathrm{O}_{5}$ : C 43.66, $\mathrm{H} 4.63, \mathrm{~N} 21.44$. Found: $\mathrm{C} 43.48, \mathrm{H}$ 4.72, N 21.34.

$\mathrm{Eu}\left(\mathrm{L}^{1}\right)_{3}\left(\mathrm{H}_{2} \mathrm{O}\right)_{4}(\mathrm{I})$. The dry $\mathrm{HL}$ ligand $(0.12 \mathrm{mmol})$ was dissolved in water solution of $\mathrm{KOH}$ or $\mathrm{NaHCO}_{3}(0.12 \mathrm{mmol})$, stirred with a heated magnetic stirrer $\left(15 \mathrm{~min}, 80^{\circ} \mathrm{C}\right)$ and added to $\mathrm{EuCl}_{3} \cdot 6 \mathrm{H}_{2} \mathrm{O}(0.04 \mathrm{mmol})$ dissolved in water. The resulting solution was filtered and dried in air for recrystallization. As a result, a poorly emitting materials I and II were obtained using $\mathrm{KOH}$ and $\mathrm{NaHCO}_{3}$, respectively.

$\mathrm{Eu}\left(\mathrm{L}^{2}\right)_{3}\left(\mathrm{H}_{2} \mathrm{O}\right)_{4}$ (III). The dry $\mathrm{HL}^{2}$ ligand $(0.089 \mathrm{mmol})$ was dissolved in water solution of $\mathrm{KOH}(0.089 \mathrm{mmol})$, stirred using a heated magnetic stirrer $\left(15 \mathrm{~min}, 80^{\circ} \mathrm{C}\right)$ and added to $\mathrm{EuCl}_{3} \cdot 6 \mathrm{H}_{2} \mathrm{O}$ dissolved in water $(0.03 \mathrm{mmol})$. The resulting solution was filtered and dried in air for recrystallization. As a result, luminescent complex III Eu( $\left.\mathrm{L}^{2}\right)_{3}\left(\mathrm{H}_{2} \mathrm{O}\right)_{4}$ was obtained.

$\mathrm{Eu}\left(\mathrm{L}^{3}\right)_{3}\left(\mathrm{H}_{2} \mathrm{O}\right)_{4}$ (IV). The dry ligand $\mathrm{H}_{3} \mathrm{~L}^{3}(0.134 \mathrm{mmol})$ was dissolved in water solution of $\mathrm{KOH}(0.402 \mathrm{mmol})$, stirred using a heated magnetic stirrer $\left(15 \mathrm{~min}, 80^{\circ} \mathrm{C}\right)$, and added to $\mathrm{EuCl}_{3} \cdot 6 \mathrm{H}_{2} \mathrm{O}$, dissolved in water $(0.134 \mathrm{mmol})$. The resulting solution was filtered and dried in air for recrystallization. After drying, it was centrifuged 2 times ( 5 min each). As a result, the luminescence complex IV Eu( $\left.\mathrm{L}^{3}\right)_{3}\left(\mathrm{H}_{2} \mathrm{O}\right)_{4}$ was obtained.

$\mathrm{Eu}_{4}\left(\mathrm{~L}^{4}\right)^{4}{ }_{3}\left(\mathrm{H}_{2} \mathrm{O}\right)_{4}(\mathrm{~V})$. The dry ligand $\mathrm{H}_{4} \mathrm{~L}^{4}(0.05 \mathrm{mmol})$ was dissolved in water solution of $\mathrm{KOH}(0.22 \mathrm{mmol})$, stirred using a heated magnetic stirrer $\left(15 \mathrm{~min}, 80^{\circ} \mathrm{C}\right)$, and added to $\mathrm{EuCl}_{3} \cdot 6 \mathrm{H}_{2} \mathrm{O}$, dissolved in water $(0.073 \mathrm{mmol})$. The resulting solution was filtered and dried in air for recrystallization. After drying, it was centrifuged 2 times ( $5 \mathrm{~min}$ each). As a result, the luminescence complex $\mathrm{V} \mathrm{Eu} \mathrm{Eu}_{4}\left(\mathrm{~L}^{4}\right)^{4}{ }_{3}\left(\mathrm{H}_{2} \mathrm{O}\right)_{4}$ was obtained.

$\mathrm{Eu}_{2}\left(\mathrm{~L}^{5}\right)_{3}\left(\mathrm{H}_{2} \mathrm{O}\right)_{4}(\mathrm{VI})$. Dry ligand $\mathrm{H}_{2} \mathrm{~L}^{5}(0.144 \mathrm{mmol})$ was dissolved in water solution of $\mathrm{KOH}(0.289 \mathrm{mmol})$, stirred using a heated magnetic stirrer $\left(15 \mathrm{~min}, 80^{\circ} \mathrm{C}\right)$, and added to $\mathrm{EuCl}_{3} \cdot 6 \mathrm{H}_{2} \mathrm{O}$, dissolved in water $(0.096 \mathrm{mmol})$. The resulting solution was filtered and dried in air for recrystallization. As a result, luminescent complex $\mathrm{VI} \mathrm{Eu}_{2}\left(\mathrm{~L}^{5}\right)_{3}\left(\mathrm{H}_{2} \mathrm{O}\right)_{4}$ was obtained.

$\mathrm{Tb}_{2}\left(\mathrm{~L}^{5}\right)_{3}\left(\mathrm{H}_{2} \mathrm{O}\right)_{4}$ (VII). Dry ligand $\mathrm{H}_{2} \mathrm{~L}^{5}(0.144 \mathrm{mmol})$ was dissolved in water solution of $\mathrm{KOH}(0.289 \mathrm{mmol})$, stirred using a heated magnetic stirrer $\left(15 \mathrm{~min}, 80^{\circ} \mathrm{C}\right)$, and added to $\mathrm{TbCl}_{3} \cdot 6 \mathrm{H}_{2} \mathrm{O}$, dissolved in water $(0.096 \mathrm{mmol})$. The resulting solution was filtered and dried in air for recrystallization. As a result, luminescent complex VII Tb $2\left(\mathrm{~L}^{5}\right)_{3}\left(\mathrm{H}_{2} \mathrm{O}\right)_{4}$ was obtained.

$\mathrm{Eu}_{2}\left(\mathrm{~L}^{6}\right)_{3}\left(\mathrm{H}_{2} \mathrm{O}\right)_{4}$ (VIII). Dry ligand $\mathrm{H}_{2} \mathrm{~L}^{6}(0.118 \mathrm{mmol})$ was dissolved in water solution of $\mathrm{KOH}(0.236 \mathrm{mmol})$, stirred using a heated magnetic stirrer $\left(15 \mathrm{~min}, 80^{\circ} \mathrm{C}\right)$, and added to $\mathrm{EuCl}_{3} \cdot 6 \mathrm{H}_{2} \mathrm{O}$, dissolved in water $(0.079 \mathrm{mmol})$. The resulting solution was filtered and dried in air for recrystallization. As a result, luminescent complex VIII $\mathrm{Eu}_{2}\left(\mathrm{~L}^{6}\right)_{3}\left(\mathrm{H}_{2} \mathrm{O}\right)_{4}$ was obtained.

$\mathrm{Tb}_{2}\left(\mathrm{~L}^{6}\right)_{3}\left(\mathrm{H}_{2} \mathrm{O}\right)_{4}(\mathrm{IX})$. The dry $\mathrm{H}_{2} \mathrm{~L}^{6}$ ligand $(0.118 \mathrm{mmol})$ was dissolved in water solution $\mathrm{KOH}(0.236 \mathrm{mmol})$, stirred using a heated magnetic stirrer $\left(15 \mathrm{~min}, 80^{\circ} \mathrm{C}\right)$, and added to $\mathrm{TbCl}_{3} \cdot 6 \mathrm{H}_{2} \mathrm{O}$, dissolved in water $(0.079 \mathrm{mmol})$. The resulting solution was filtered and dried in air for recrystallization. As a result, luminescent complex IX $\mathrm{Tb}_{2}\left(\mathrm{~L}^{6}\right)_{3}\left(\mathrm{H}_{2} \mathrm{O}\right)_{4}$ was obtained.

$\mathrm{Eu}_{2}\left(\mathrm{~L}^{7}\right)_{3}\left(\mathrm{H}_{2} \mathrm{O}\right)_{4}(\mathrm{X})$. Dry ligand $\mathrm{K}_{2} \mathrm{~L}^{7}(0.287 \mathrm{mmol})$ was stirred using a heated magnetic stirrer $\left(15 \mathrm{~min}, 80^{\circ} \mathrm{C}\right)$, and added to $\mathrm{EuCl}_{3} \cdot 6 \mathrm{H}_{2} \mathrm{O}$, dissolved in ethanol $(0.19 \mathrm{mmol})$. The resulting solution was evaporated and left in a closed state, filtered with a filter nozzle and a syringe and dried in air for recrystallization. As a result, luminescent complex $\mathbf{X}$ $\mathrm{Eu}_{2}\left(\mathrm{~L}^{7}\right)_{3}\left(\mathrm{H}_{2} \mathrm{O}\right)_{4}$ was obtained.

$\mathrm{Eu}_{2}\left(\mathrm{~L}^{7}\right)_{3}(\mathrm{Phen})(\mathrm{XI})$. Dry ligand $\mathrm{K}_{2} \mathrm{~L}^{7}(0.19 \mathrm{mmol})$ was stirred using a heated magnetic stirrer $\left(15 \mathrm{~min}, 80^{\circ} \mathrm{C}\right)$, and added to an ethanol solution of a mixture of $\mathrm{EuCl}_{3} \cdot 6 \mathrm{H}_{2} \mathrm{O}$ and Phen $(0.127 \mathrm{mmol})$. The resulting solution was filtered using a filter nozzle and a syringe and dried in air for recrystallization.

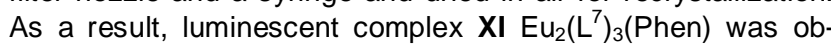
tained.

\section{Results and Discussion}

In this work, europium complexes with triazole-containing anions of substituted pyrazoles were selected as the objects of research, and the main task was to establish the possibility of obtaining such compounds, as well as the presence of their luminescent properties. On the other hand, it was important to identify the effect of triazole fragments on luminescence quenching and the dependence of luminescence intensity on other functional groups in the ligand. Keeping this in mind, the practical goal was to establish the possibility of using luminescence of these compounds for phosphine oxide sensing an example of TPPO.

\section{Synthesis and characterization}

All the complexes were obtained by the exchange reaction between europium chlorides and potassium salts obtained by ligand deprotonation in the $\mathrm{KOH}$ solution, which was possible thanks to the sufficient acidity of the selected triazole derivatives. The composition of the compounds was established based on IR and NMR spectroscopy data, as well as on TGA data with mass-spectroscopic analysis of the evolved gases. In the ${ }^{1} \mathrm{H}$ NMR spectra of the obtained complexes, the same signals were observed in the spectra of corresponding ligands, while their shift and broadening, resulting from the proximity of the paramagnetic europium ion, witnesses the formation of the complex. In particular, the largest broadening and shift was observed for the signals nearest to the deprotonated $\mathrm{NH}$-group, which is exemplified in Figure 1 on example of $\mathrm{K}_{2} \mathrm{~L}^{7}$ and $\mathbf{X}$. Such a feature is another evidence of the complex, and it is not just the formation of ligand-europium mixture.

NMR spectroscopy was particularly informative in the analysis of the mixed-ligand complex XI. Here, the anionic-toneutral ligand ratio, which was found to be $3: 1$, was calculated based on the proton signals integration (Figure 2).

Both IR spectroscopy and TGA data witnessed the formation of hydrated complexes (Figure 3 ). This is indicated by the broad band at ca. $3000-3600 \mathrm{~cm}^{-1}$ in the IR spectra, as well as by the low-temperature weight loss, accompanied by the peak in the ionic current with $m / z=18$, corresponding to water in the TGA data.

This allows concluding the obtaining of the above- 


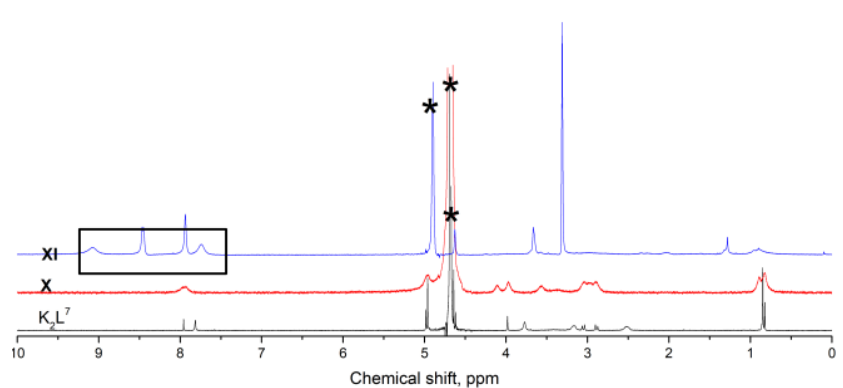

Figure $2{ }^{1} \mathrm{H}$ NMR spectra $\mathrm{K}_{2} \mathrm{~L}^{7}, \mathbf{X}$, and $\mathbf{X I}$ in $\mathrm{D}_{2} \mathrm{O}$. Solvent signal is marked with a star. Phen proton signals are framed.
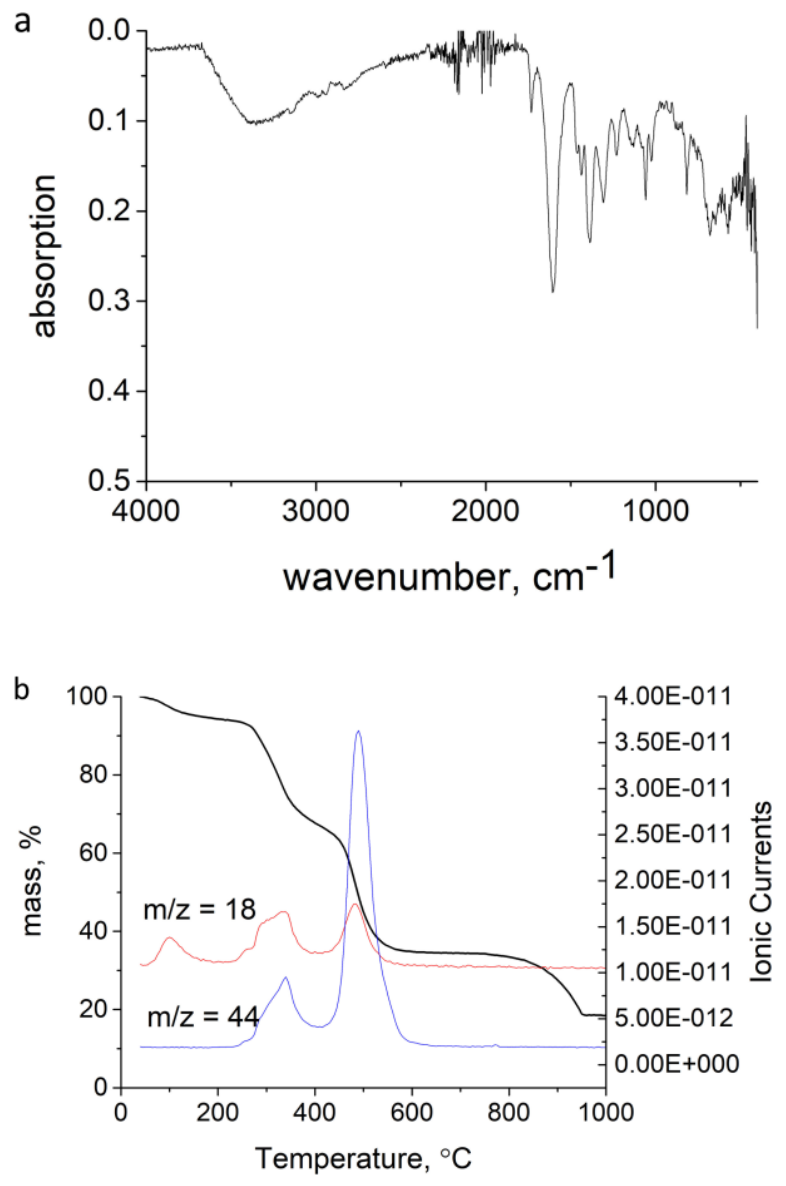

Figure 3 (a) IR spectrum and (b) TGA curve, as well as ionic currents with $\mathrm{m} / \mathrm{z}=18$ (water, red) and $44\left(\mathrm{CO}_{2}\right.$, blue) of $\mathbf{X}$.

mentioned complexes, as well as to determine their composition. However, very important information on the peculiarities of their formation was obtained using luminescence spectroscopy.

\section{Luminescent properties}

We immediately noticed that the triazole in the ligand actually leads to the quenching of the luminescence of all the obtained complexes-both of europium and terbium. The luminescence of these compounds was either low-intensity or absent. When discussing the results, we will compare the luminescence intensity of the new compounds among each other. However, in comparison with the high-intensity emitters based on other terbium and europium coordination compounds, the luminescence intensity of all these compounds is low.
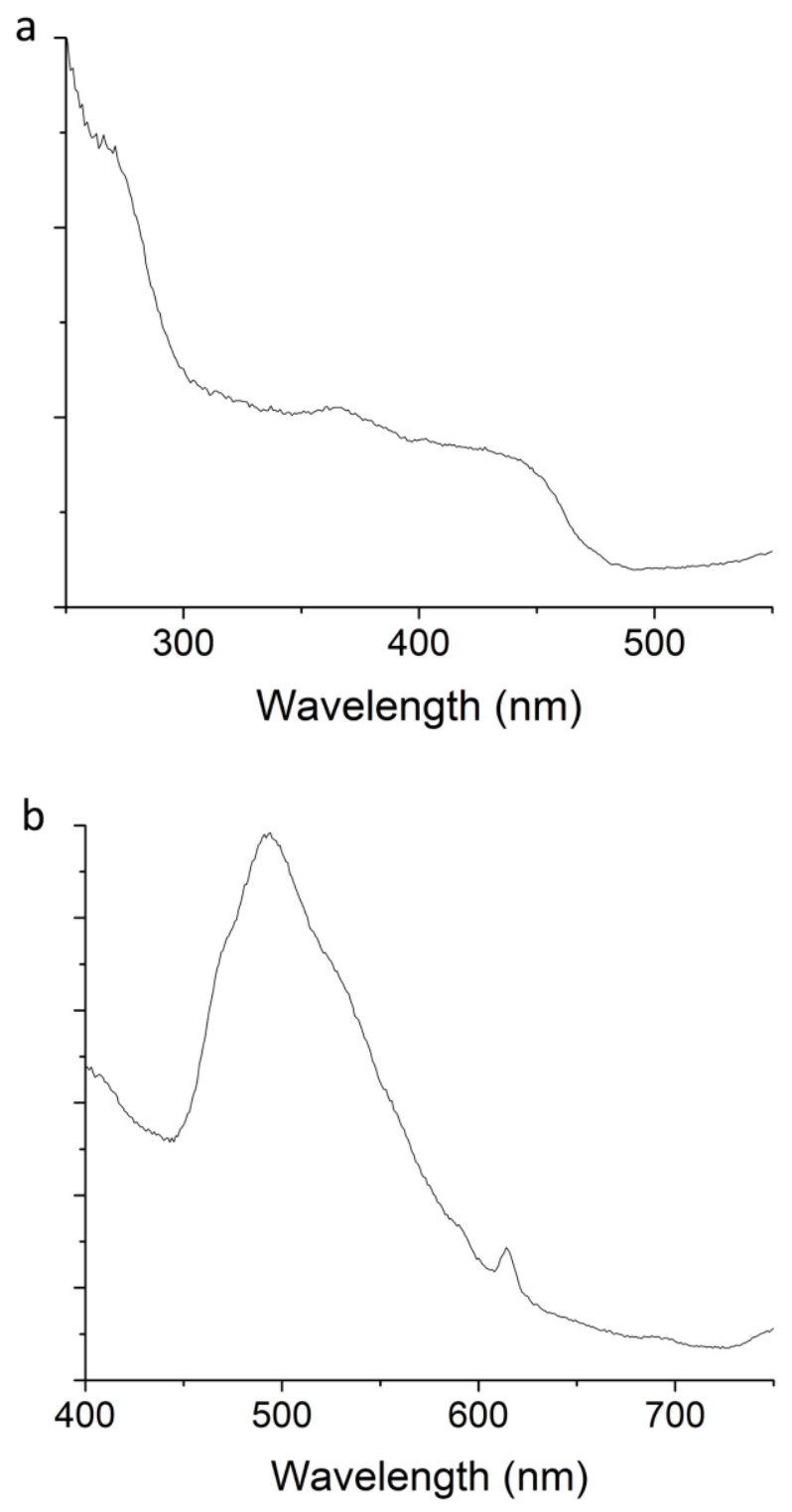

Figure 4 (a) Excitation and (b) luminescence spectra of III.

In the spectrum of III, europium ionic luminescence is not observed, and its spectrum is represented by only ligand luminescence (Figure 4).

Apparently, in this case, the luminescence of europium was absent due to the fact that the triplet level of the ligand is lower in energy than in the excited state of europium. Thus, energy transfer to europium is not observed. This is evidenced by the fact that III does not only lack the luminescence of europium but also demonstrate rather high intensity of the ligand luminescence.

Next, we compared the luminescence of europium complexes I, II, and IV with the $\mathrm{HL}^{1}$ (I and II) and $\mathrm{H}_{3} \mathrm{~L}^{3}$ ligands (IV, see Experimental). It is important that the $\mathrm{HL}^{1}$ ligand is an ester of $\mathrm{H}_{3} \mathrm{~L}^{3}$ acid. As a result, the complex IV with the anion of $\mathrm{H}_{3} \mathrm{~L}^{3}$ acid has a noticeable luminescence of europium, whereas the complex with the $\mathrm{HL}^{1}$ anion either does not emit at all, or emits extremely weakly, depending on the synthesis technique, during which the deprotonation of the ligand is carried out (compounds I and II). When a weaker base $\mathrm{NaHCO}_{3}$ was used for deprotonation, only the $\mathrm{NH}$ group is deprotonated, and the obtained complex II demonstrates no luminescence. When the 

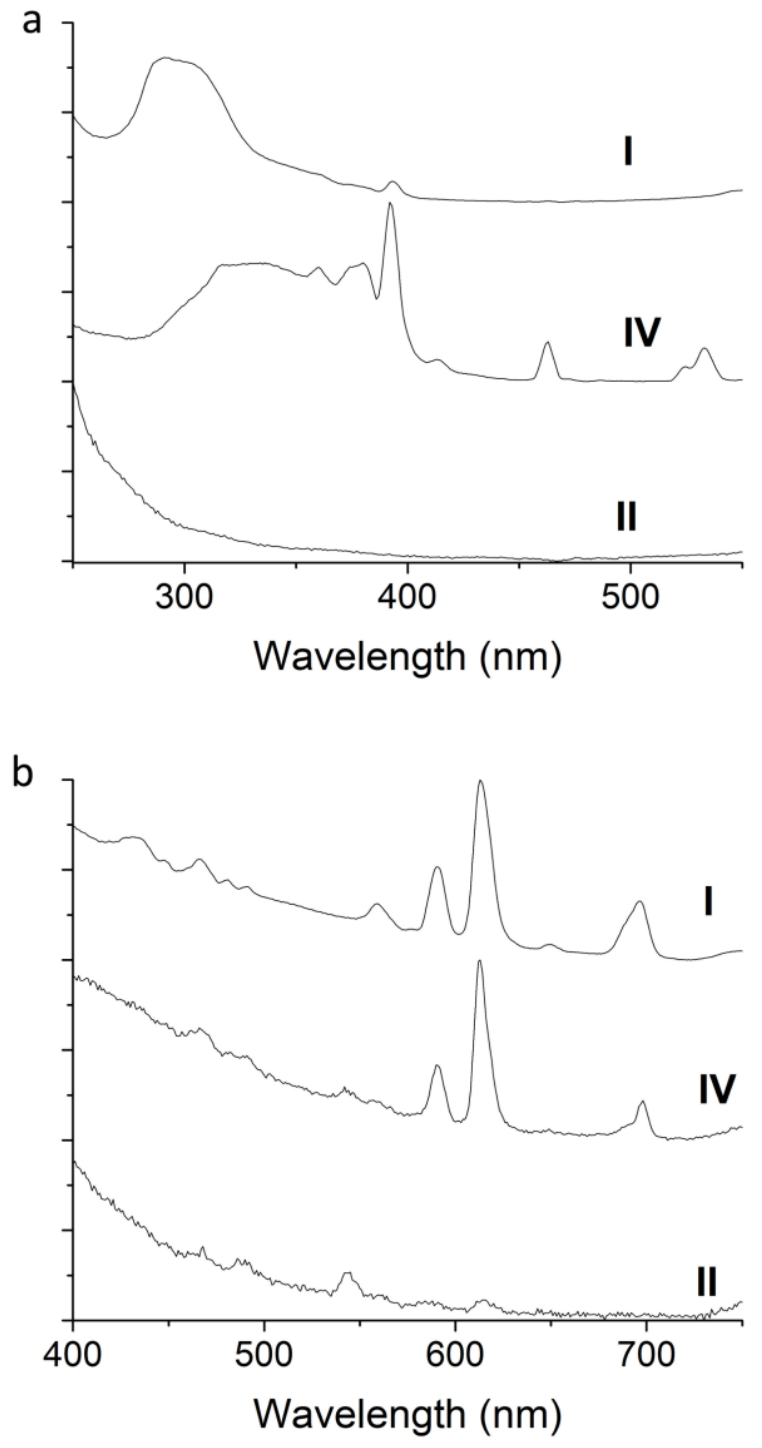

Figure 5 (a) Excitation and (b) luminescence spectra of I, II, and IV.

stronger potassium hydroxide is used, hydrolysis of ester groups takes place with partial formation of $\mathrm{H}_{3} \mathrm{~L}^{3}$ acid, resulting in the appearance of faint luminescence of $I$.

It signifies that the anion of the $\mathrm{H}_{3} \mathrm{~L}^{3}$ ligand sensitizes the luminescence of europium, unlike the anion of the $\mathrm{HL}^{1}$ ligand. Thus, complex I, where the $\mathrm{HL}^{1}$ ligand was deprotonated with $\mathrm{KOH}$, is most likely to be a mixture of II and IV, i.e., europium complexes with $\left(\mathrm{L}^{1}\right)$ ligand and with $\left(\mathrm{L}^{3}\right)^{3-}$, which was partially formed during the synthesis of $\mathbf{I}$.

Excitation spectra of I, II, and IV are in line with the conclusion made based on emission data. Therefore, the excitation spectrum of $I$ is dominated by a wide through-ligand band centered at ca. $300 \mathrm{~nm}$, while the excitation through Eu ion itself, including its most intense band at $390 \mathrm{~nm}$, corresponding to the ${ }^{7} \mathrm{~F}_{0} \rightarrow{ }^{5} \mathrm{~L}_{6}$, is less intense (Figure 5). Excitation spectrum of IV, in contrary, is dominated by through Eu excitation bands, while almost no band can be detected in the excitation spectrum of II due to almost no emission.

The $\mathrm{H}_{4} \mathrm{~L}^{4}$ ligand is a dimer of the $\mathrm{H}_{3} \mathrm{~L}^{3}$ ligand, and the luminescence of europium complexes $\mathbf{V}$ with this ligand is comparable in intensity with the one of IV. This is not surprising, and allows concluding that the bridging group, which was used
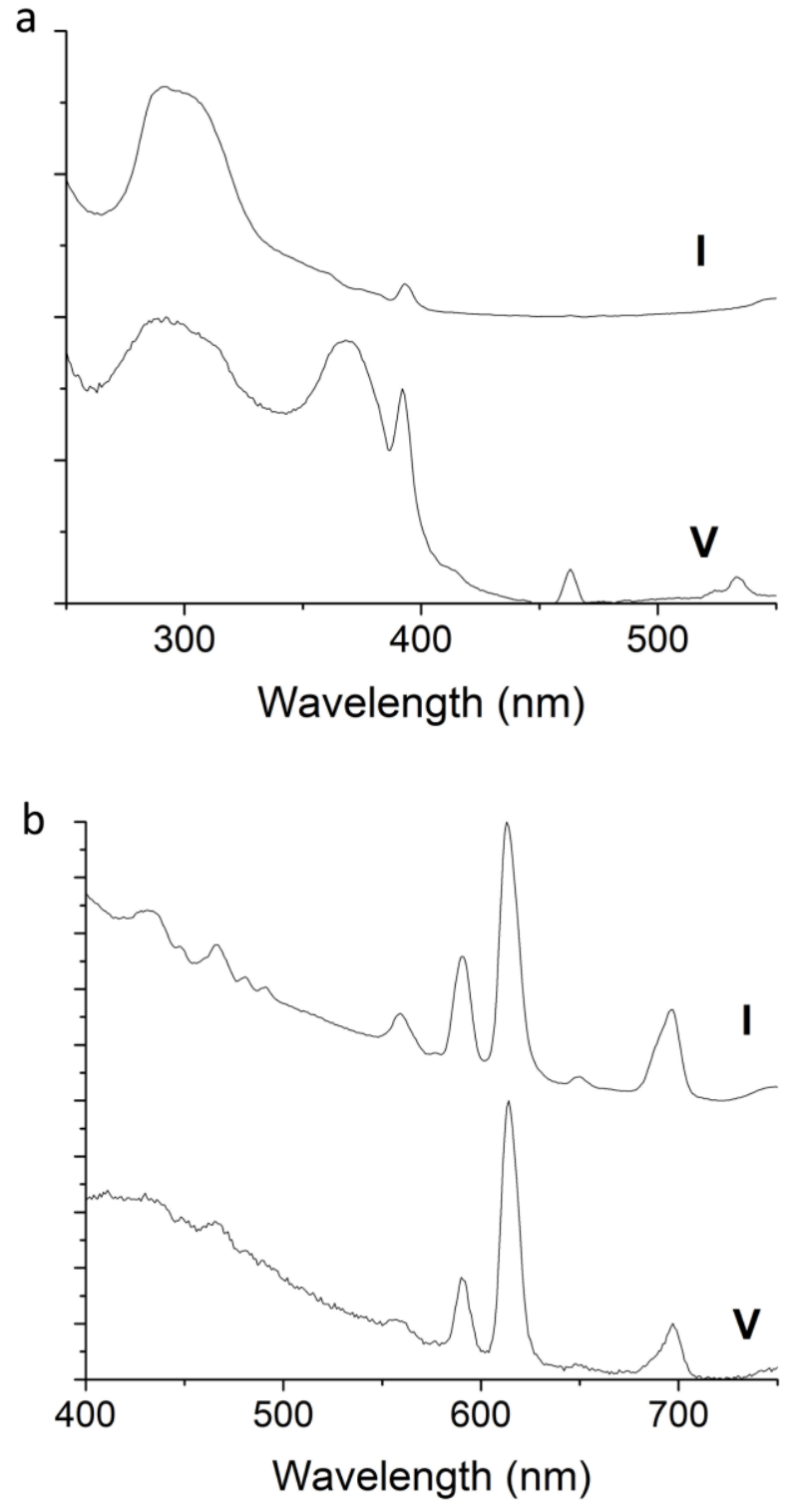

Figure 6 a) Excitation and b) luminescence spectra of $I$ and V.

to form a dimer, does not affect the luminescent properties. Thus, the formation of a dimer using such a group does not harm luminescence and can also be further used for the formation of conjugates. Excitation spectrum of $\mathbf{V}$ is dominated by a wide through-ligand band with less intense through Eu excitation bands and resembles the one of I except for the appearance of an additional through-ligand excitation band at ca. $370 \mathrm{~nm}$, resulted from an additional absorption due to the dimerization (Figure 6)

As for the synthesis of compounds VI and VII with the $\mathrm{H}_{2} \mathrm{~L}^{5}$ ligand, it is important to note that this ligand differs from $\mathrm{H}_{3} \mathrm{~L}^{3}$ in the absence of a second carboxy-group, instead of which there is an $\mathrm{OH}$-group, which is known for its ability to quench europium luminescence. As a result, we observe low luminescence intensity of both the europium complex and the terbium complex.

It is important to show that the quenching of the luminescence of terbium VII with this ligand is not related to the lack of energy transfer from the ligand to the terbium ion, since the energy of the excited state of the terbium ion is higher than that of the europium ion (Figure 7). To this end, we examined 
a
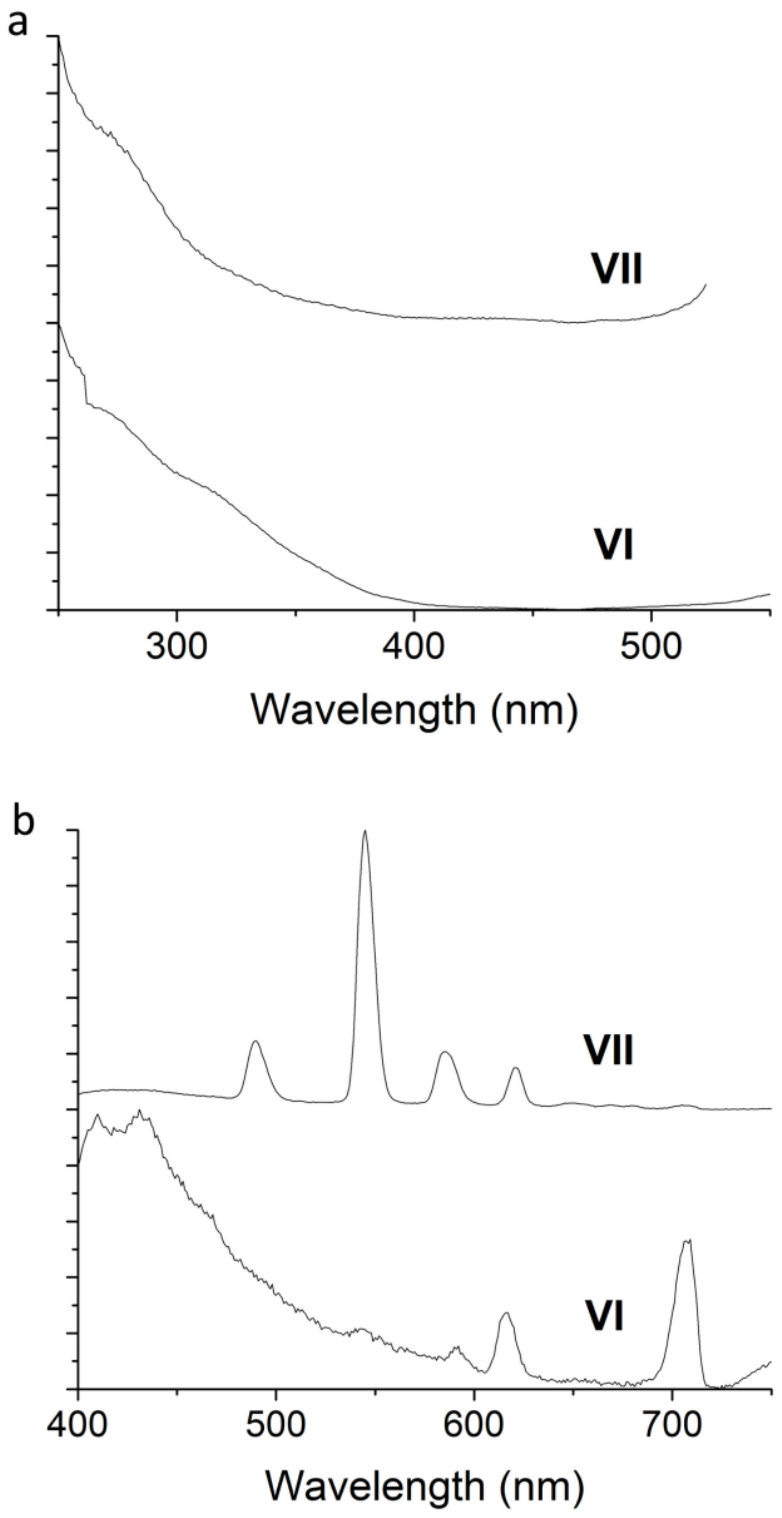

Figure 7 (a) Excitation and (b) luminescence spectra VI and VII.

the ligand $\mathrm{H}_{2} \mathrm{~L}^{6}$, which is also synthesized as a complex with europium and terbium. These two ligands differ in replacing the hydroxyl group with phenyl. In this case, the energy of the triplet ligand equation could only decrease, since we introduced an additional conjugated fragment. If terbium luminescence was not observed in the case of VI due to the low triplet level of the ligand, terbium luminescence should not be observed in the case of VIII either. However, luminescence IX was observed, which suggests that the quenching of the terbium ion with a low energy triplet level is not associated in the case of VII.

In the cases of VIII and IX, low-intensity, luminescence of europium and terbium was observed, which is associated with the introduction of another phenyl group, which increases absorption. It remains lower than in the case of $\mathrm{H}_{2} \mathrm{~L}^{5}$, but it is sufficient to observe the luminescence of europium and terbium ions (Figure 8).

Complex $\mathbf{X}$ contains an anion of $\left(\mathrm{L}^{7}\right)^{2-}$, which differs from $\left(\mathrm{L}^{4}\right)^{4-}$ in the absence of two pyrazole rings. As a result, $\mathrm{K}_{2} \mathrm{~L}^{7}$ represents a potassium carboxylate with an anion of not an $\mathrm{NH}$-acid. The formed compound $\mathbf{X}$ demonstrated detectable a

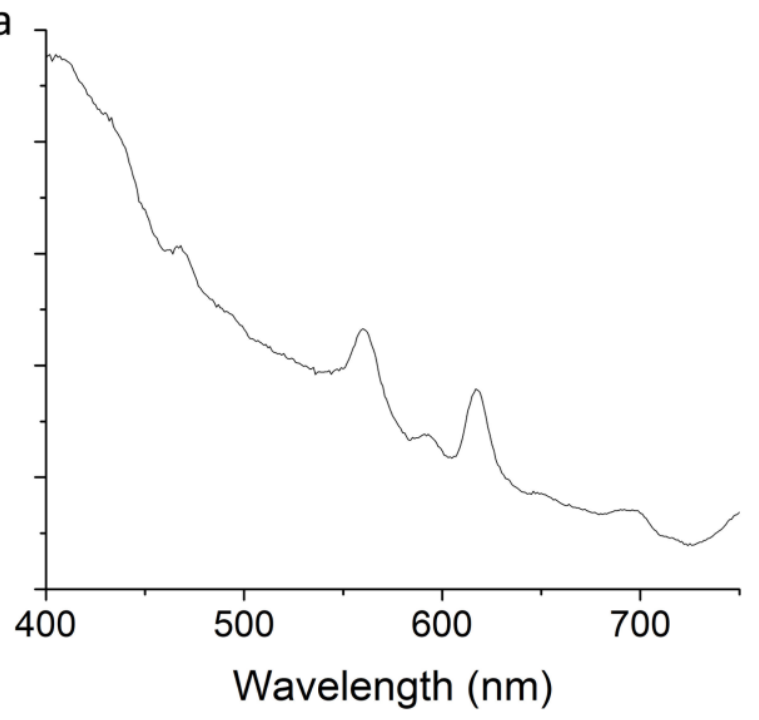

b

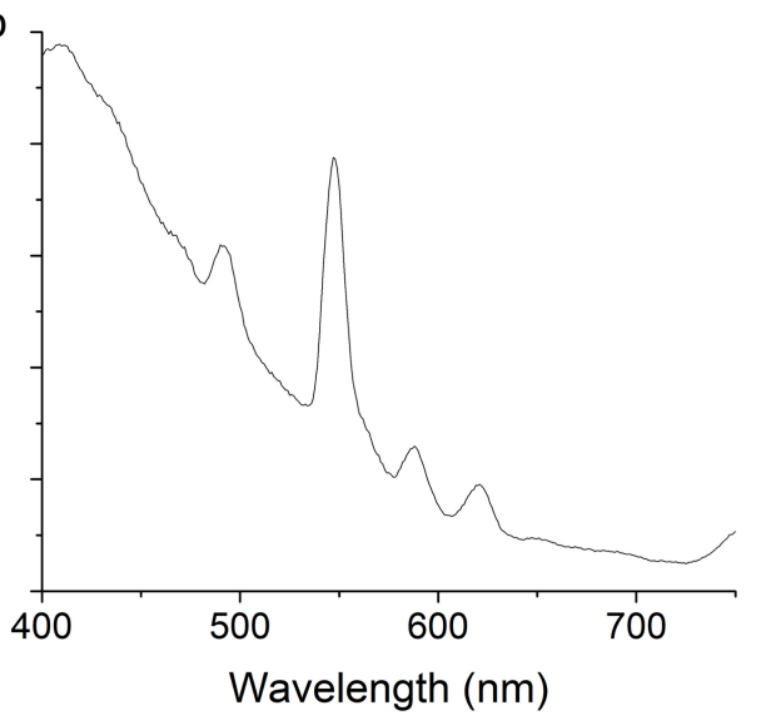

Figure 8 Luminescence spectra of (a) VIII and (b) IX.

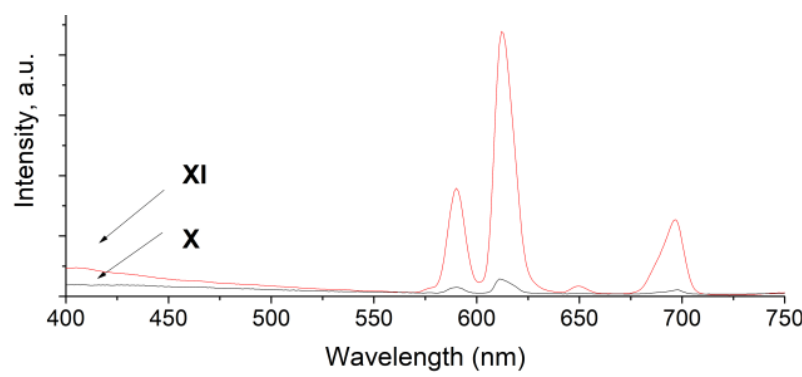

Figure 9 Luminescence spectra of $\mathbf{X}$ and $\mathbf{X I}$.

europium-based luminescence, whose intensity can expectedly be further increased by the introduction of the Phen ligand, which is well-known for its possibility to sensitize europium luminescence. In Figure 9, the luminescence spectra of $\mathbf{X}$ and $\mathbf{X I}$ in ethanol solutions of the same concentration are given, representing the relative luminescence intensity of these complexes.

\section{Sensory properties}

Based on this data, we selected three complexes as potential TPPO sensor materials that have a detectable 
europium luminescence of different intensity, i.e., VI, $\mathbf{X}$, and $\mathbf{X I}$. To the ethanol solutions of TPPO was added dropwise (drop volume equaled to $5 \mu \mathrm{L}$ ), and the luminescence spectra were recorded.

The study revealed that luminescence of both $\mathbf{V I}$ and $\mathbf{X}$ was immediately quenched after the first drop of TPPO solution, meaning that these materials cannot be used for TPPO detection (Figure 10). At the same time, complex XI containing Phen ligand demonstrated gradual luminescence intensity decrease upon TPPO added volume.
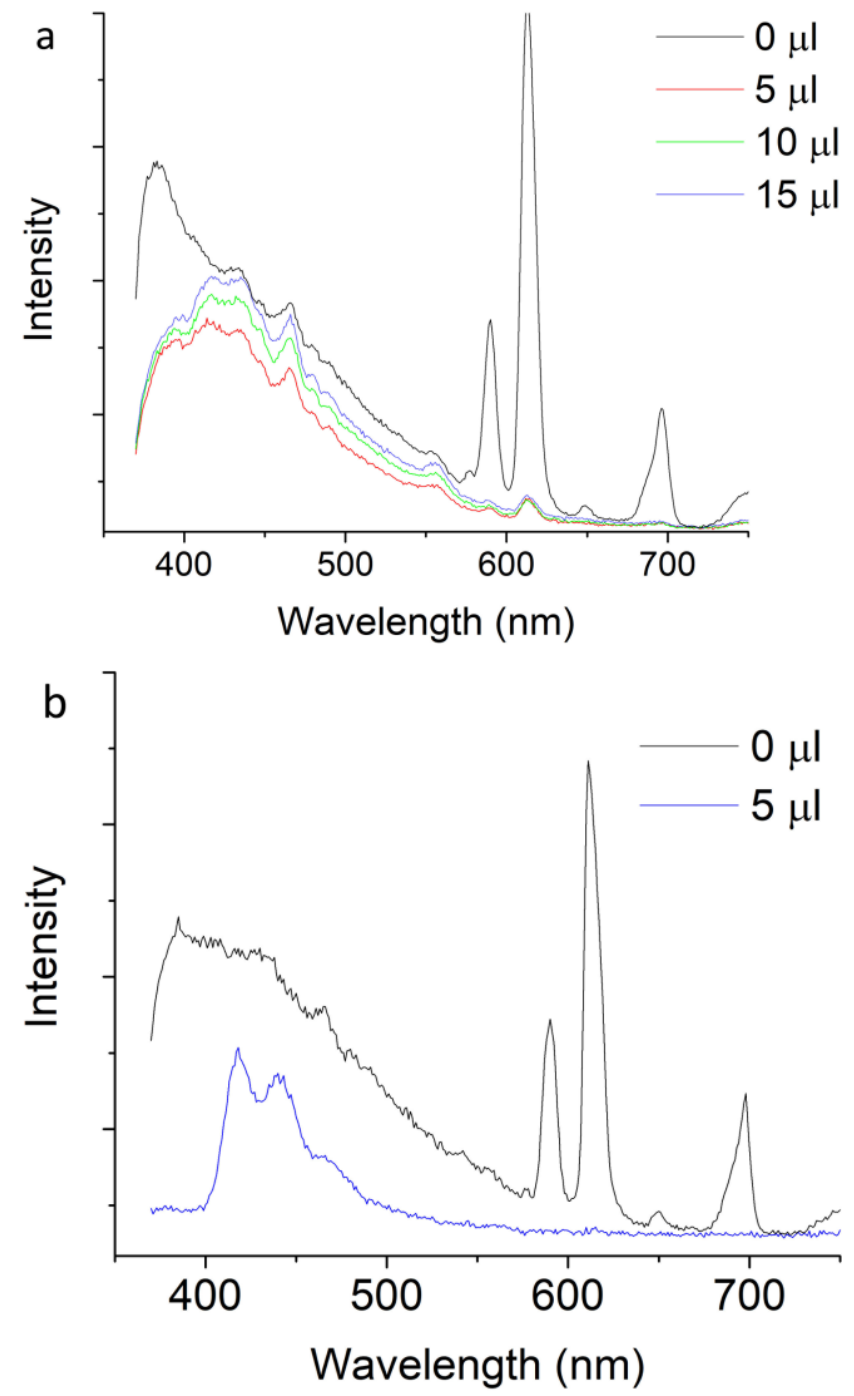

Figure 10 Luminescence spectra of ethanol solutions of (a) VII and (b) IX upon added TPPO solution in ethanol.

The dependence of the $\mathbf{X I}$ luminescence intensity on added TPPO solution volume was studied, and the intensity at $612 \mathrm{~nm}$ was plotted (Figure 11). It revealed the decreasing dependence, which can be used for the determination of the TPPO presence and concentration. The sensitivity was characterized by a logarithmic derivative of luminescence intensity (I) on TPPO concentration $(c)$ as:

$$
\mathrm{Sr}=(1 / /) \times(\mathrm{d} / / \mathrm{d} c)
$$

It increased upon the decrease of the added TPPO concentration and reached $9 \% / \mu \mathrm{L}$, making it particularly sensitive to the small concentrations of TPPO.

\section{Conclusions}

It was demonstrated that the triazole group quenches luminescence of both europium and terbium. At the same time,
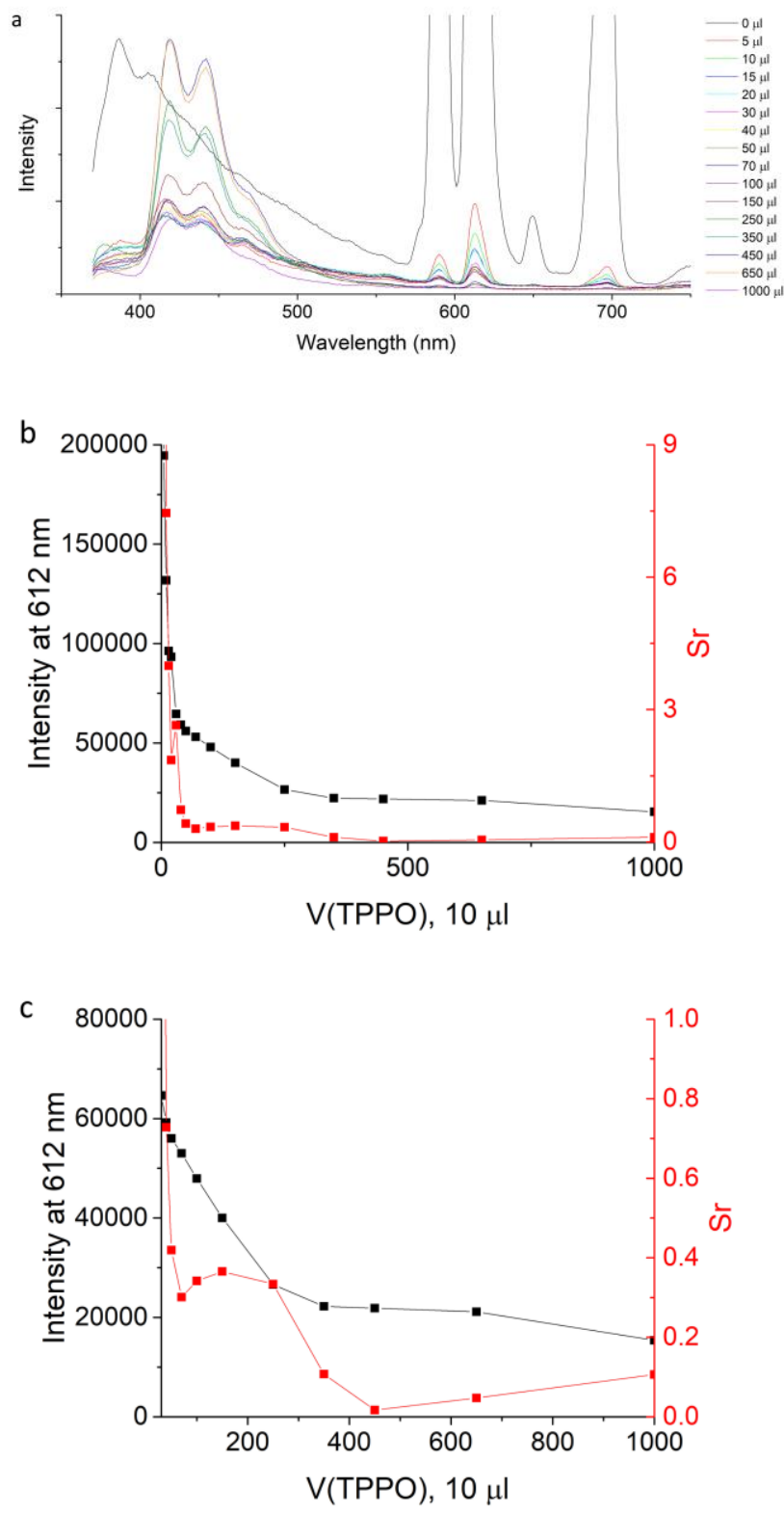

Figure 11 (a) Luminescence spectra of ethanol solution of $\mathbf{X I}$ upon added TPPO solution in ethanol (b), and (c) luminescence intensity at $612 \mathrm{~nm}$ depending on the added TPPO volume.

the addition of a sufficient number of conjugated fragments, which leads to high absorption of ligands, makes it possible to obtain europium complexes with noticeable luminescence. The formation of a dimer using a bispidine framework does not affect luminescent properties and can be used for the formation of luminescent conjugates.

Among the studied compounds, complex XI demonstrates enough luminescence, which can be easily quenched in the presence of TPPO at the same time. This allowed to successfully use it as sensors for phosphine oxides, in particular TPPO, with the sensitivity of up to $9 \% / \mu \mathrm{L}$.

\section{Acknowledgement}

Authors thank RFBR and President's grant (No. MK-2799.2019.3).

\section{Conflict of Interest}

The authors declare no conflict of interest. 
Copyright (c) 2020 Jae Hoon Kim, A. I. Dalinger, A. V. Medvedko, E. V. Latipov, S. Z. Vatsadze, and V. V. Utochnikova. This article is an open access article distributed under the terms and conditions of the Creative Commons Attribution (CC BY) license (http://creativecommons.org/ licenses/by/4.0/). The use, distribution or reproduction in other forums is permitted, provided the original author(s) or licensor are credited and that the original publication in this journal is cited, in accordance with accepted academic practice. No use, distribution or reproduction is permitted which does not comply with these terms.

\section{References}

[1] Bünzli, J. C. G.; Comby, S.; Chauvin, A. S.; Vandevyver, C. D. B. New Opportunities for Lanthanide Luminescence. J. Rare Earths 2007, 25, 257-274.

[2] Bünzli, J. C. G.; Chauvin, A. S.; Kim, H. K.; Deiters, E.; Eliseeva, S. V. Lanthanide Luminescence Efficiency in Eight- and Nine-Coordinate Complexes: Role of the Radiative Lifetime. Coord. Chem. Rev. 2010, 254, 2623-2633.

[3] Amoroso, A. J.; Pope, S. J. A. Using Lanthanide lons in Molecular Bioimaging. Chem. Soc. Rev. 2015, 44, 4723-4742.

[4] Bünzli, J. C. G. Luminescence Bioimaging with Lanthanide Complexes. In Lumin. Lanthan. Ions Coord. Compd. Nanomater, Ed.: De Bettencourt-Dias, A., Wiley, UK, 2014, Vol. 4, pp. 125-196.

[5] Bünzli, J. C. G. Lanthanide Light for Biology and Medical Diagnosis. J. Lumin. 2016, 170, 866-878.

[6] Liao, Z.; Tropiano, M.; Mantulnikovs, K.; Faulkner, S.; Vosch, T.; Just Sørensen, T. Spectrally Resolved Confocal Microscopy Using Lanthanide Centred Near-IR Emission. Chem. Commun. (Cambridge, U. K.) 2015, 51, 2372-2375.

[7] Utochnikova, V. V.; Kalyakina, A. S.; Bushmarinov, I. S.; Vashchenko, A. A.; Marciniak, L.; Kaczmarek, A. M.; Van Deun, R.; Bräse, S.; Kuzmina, N. P. Lanthanide 9-Anthracenate: Solution Processable Emitters for Efficient Purely NIR Emitting Host-Free OLEDs. J. Mater. Chem. C 2016, 4, 9848-9855.

[8] Grishko, A. Y.; Utochnikova, V. V.; Averin, A. A.; Mironov, A. V.; Kuzmina, N. P. Unusual Luminescence Properties of Heterometallic REE Terephthalates. Eur. J. Inorg. Chem. 2015, 1660-1664.

[9] Utochnikova, V. V.; Pietraszkiewicz, O.; Koźbiał, M.; Gierycz, P.; Pietraszkiewicz, M.; Kuzmina, N. P. Mixed-Ligand Terbium Terephthalates: Synthesis, Photophysical and Thermal Properties and Use for Luminescent Terbium Terephthalate Thin Film Deposition. J. Photochem. Photobiol. A 2013, 253, 72-80.

[10] Daiguebonne, C.; Kerbellec, N.; Guillou, O.; Bünzli, J.-C.; Gumy, F.; Catala, L.; Mallah, T.; Audebrand, N.; Gérault, Y.; Bernot, K.; Calvez, G. Structural and Luminescent Properties of Micro- and Nanosized Particles of Lanthanide Terephthalate Coordination Polymers. Inorg. Chem. 2008, 47, 3700-3708.

[11] Wan, Y.; Zhang, L.; Jin, L.; Gao, S.; Lu, S. High-Dimensional Architectures from the Self-Assembly of Lanthanide lons with Benzenedicarboxylates and 1,10-Phenanthroline. Inorg. Chem. 2003, 42, 4985-4994.

[12] Tsaryuk, V. I.; Zhuravlev, K. P.; Vologzhanina, A. V.; Kudryashova, V. A.; Zolin, V. F. Structural Regularities and Luminescence Properties of Dimeric Europium and Terbium Carboxylates with 1,10-Phenanthroline (C.N. = 9). J. Photochem. Photobiol. A 2010,
$211,7-19$

[13] Ahmed, Z.; Iftikhar, K. Sensitization of Visible and NIR Emitting Lanthanide(III) Ions in Noncentrosymmetric Complexes of Hexafluoroacetylacetone and Unsubstituted Monodentate Pyrazole. J. Phys. Chem. A 2013, 117, 11183-11201.

[14] Listkowski, A.; Osińska, W.; Mohanraj, J.; Pietraszkiewicz, M.; Dutkiewicz, G.; Borowiak, T. Synthesis and Photoluminescence Properties of Novel Lanthanide Complexes Based on Pyrazolone Schiff Bases. Synth. Met. 2012, 162, 1285-1291.

[15] Sun, L.; Qiu, Y.; Liu, T.; Zhang, J. Z.; Dang, S.; Feng, J.; Wang, Z.; Zhang, H.; Shi, L. Near Infrared and Visible Luminescence from Xerogels Covalently Grafted with Lanthanide $\left[\mathrm{Sm}^{3+}, \mathrm{Yb}^{3+}, \mathrm{Nd}^{3+}\right.$, $\left.\mathrm{Er}^{3+}, \mathrm{Pr}^{3+}, \mathrm{Ho}^{3+}\right] \quad \beta$-Diketonate Derivatives Using Visible Light Excitation. ACS Appl. Mater. Interfaces 2013, 5, 9585-9593.

[16] Martins, J. P.; Martín-Ramos, P.; Coya, C.; Álvarez, A. L.; Pereira, L. C.; Díaz, R.; Martín-Gil, J.; Ramos Silva, M. Lanthanide Tetrakis- $\beta$ Diketonate Dimers for Solution-Processed OLEDs. Mater. Chem. Phys. 2014, 147, 1157-1164.

[17] Zuckermann, R. N.; Kerr, J. M.; Kent, S. B. H.; Moos, W. H. Efficient Method for the Preparation of Peptoids [Oligo( $N$-Substituted Glycines)] by Submonomer Solid-Phase Synthesis. J. Am. Chem. Soc. 1992, 114, 10646-10647.

[18] Kölmel, D. K.; Hörner, A.; Rönicke, F.; Nieger, M.; Schepers, U.; Bräse, S. Cell-Penetrating Peptoids: Introduction of Novel Cationic Side Chains. Eur. J. Med. Chem. 2014, 79, 231-243.

[19] Vollrath, S. B. L.; Fürniss, D.; Schepers, U.; Bräse, S. Amphiphilic Peptoid Transporters - Synthesis and Evaluation. Org. Biomol. Chem. 2013, 11, 8197-8201.

[20] Ni, B.-B.; Wang, C.; Wu, H.; Pei, J.; Ma, Y. Copper-Free Cycloaddition of Azide and Alkyne in Crystalline State Facilitated by Arene-Perfluoroarene Interactions. Chem. Commun. (Cambridge, U. K.) 2010, 46, 782-784.

[21] Ni, B. B.; Wang, K.; Yan, Q.; Chen, H.; Ma, Y.; Zou, B. Pressure Accelerated 1,3-Dipolar Cycloaddition of Azide and Alkyne Groups in Crystals. Chem. Commun. (Cambridge, U. K.) 2013, 49, 10130.

[22] Chen, H.; Ni, B.-B.; Gao, F.; Ma, Y. Pressure-Accelerated CopperFree Cycloaddition of Azide and Alkyne Groups Pre-Organized in the Crystalline State at Room Temperature. Green Chem. 2012, 14, 2703-2705.

[23] Meng, X.; Chen, H.; Xu, S.; Ma, Y. Metal-Free 1,3-Dipolar Cycloaddition Polymerization via Prearrangement of Azide and Alkyne in the Solid State. CrystEngComm 2014, 16, 9983-9986.

[24] Jenkins, A. L.; Manuel Uy, O.; Murray, G. M. Polymer Based Lanthanide Luminescent Sensors for the Detection of Nerve Agents. Anal. Commun. 1997, 34, 221-224.

[25] Yu, A.; Belousov, A. A.; Drozdov, P. P.; Verteletsky, A. A.; Prishchenko, L. I.; Livantsova, O. P. Novikova. Different lanthanide complexes with acylpyrazolones and phosphores containing ligands. Russ. J. Coord. Chem. 2013, 39, 1-6.

[26] Dalinger, A. I.; Medvedko, A. V.; Balalaeva, A. I.; Vatsadze, I. A.; Dalinger, I. L.; Vatsadze, S. Z. Synthesis of Novel Azides and Triazoles on the Basis of $1 \mathrm{H}$-Pyrazole-3(5)-Carboxylic Acids. Chem. Heterocycl. Compd. 2020, 56, 180-191.

Received March 24, 2020 Accepted May 1, 2020 